\title{
Original
}

\section{Tratamiento del cáncer renal metastásico: vigencia de la inmunoterapia}

\author{
Roberto Llarena Ibarguren \\ Servicio de Urología. Hospital de Cruces. Baracaldo, Vizcaya. España
}

\section{Resumen}

Objetivo: Evaluar la importancia y efectos de la inmunoterapia clásica en el tratamiento del cáncer renal diseminado. Material y métodos. Se revisan los datos históricos de los estudios realizados con citocinas, interferon e interleukina, evaluando sus combinaciones, y comparando los diferentes estudios relevantes existentes.

Comentarios: Aunque diversos, los resultados son pobres en cuanto a respuesta objetivable y en cuanto a duración de la misma, observando series ya históricas que empleando interleukina2 lograron, pesar de graves efectos secundarios, remisiones incluso completas de la enfermedad.

Conclusiones: En la actualidad y tras el advenimiento de los nuevos fármacos, el empleo de la inmunoterapia clásica puede encontrar indicación en pacientes concretos, con buen estado general, con nefrectomía previa por carcinoma de células claras, al menos 12 meses antes de la aparición de metástasis en un solo órgano, preferentemente pulmón, y con niveles normales de hemoglobina, calcio y lactodehidrogenasa, buscando ese pequeño porcentaje de respuestas estables y mantenidas.

Palabras clave: Inmunoterapia. Citocinas. Interferon. Interleukina.

\section{Treatment of metastatic renal cancer: current validity of immunotherapy}

\section{Abstract}

Objective: To assess the significance and effects of conventional immunotherapy for management of disseminated renal cancer.

Materials and methods: Historical data from studies conducted with cytokines, interferon, and interleukin are reviewed, their combinations are evaluated, and the different relevant studies available are compared.

Discussion: While diverse, results are poor in terms of objective response and its duration. Historical series using interleukin-2 achieved, despite severe side effects, disease remissions, some of them complete.

Conclusions: Currently, after the advent of new drugs, use of conventional immunotherapy may be indicated for specific patients with a good general condition undergoing previous nephrectomy for a clear cell carcinoma at least 12 months before occurrence of metastasis in a single organ, preferably the lung, and with normal levels of hemoglobin, calcium, and lactate dehydrogenase, looking for that small percentage of stable and sustained responses.

Keywords: Immunotherapy. Cytokines. Interferon. Interleukin.

$\mathrm{M}$ cho han variado las perspectivas terapéuticas aplicables al cáncer renal a lo largo de la historia. De todos es sabido y aceptado que el único tratamiento definitivo y curativo del carcinoma renal es el quirúrgico. Desde que Robson ${ }^{1}$ describió en 1963 la nefrectomía radical en un intento de reducir la recidiva local y la progresión a distancia de la enfermedad muchos han sido los tratamientos empleados para combatirla.

De todos es sabido que el carcinoma renal se diagnostica en un 30\% de los casos como enfermedad avanzada. Asimismo sabemos que el 30\% de los casos presumiblemente localizados desarrollará enfermedad a distancia tras el primer tratamiento quirúrgico. En conjunto, el 40\% de los pacientes que sufren la enfermedad acabarán sucumbiendo a ella ${ }^{2}$.

En 2002 ya se apuntaba la incidencia en progresión de este tipo tumoral que era de 6/100.000 habitantes/año en hombres y de 2,4/100.000/año para mujeres, con un aumento anual de $7 \%$ en hombres y de $10 \%$ en mujeres ${ }^{3}$.

\section{MODALIDADES TERAPÉUTICAS EN EL CÁNCER RENAL DISEMINADO}

La quimioterapia, pilar básico en el tratamiento de las enfermedades neoplásicas, basada en diversos 
regímenes que combinaban vimblastina, 5 fluoracilo, y más recientemente la gemcitabina tan sólo ha aportado modestas mejorías en la supervivencia, con respuestas escasas casi siempre inferiores al $10 \%{ }^{4}$.

En una revisión de 72 agentes citostáticos realizada sobre 3.500 pacientes tratados entre 1983 y 1992 tan sólo se encontró una respuesta objetiva global del 5‘6\%, siendo ésta en general de corta duración. La presencia del gen MDR-1 (multi-drug resistent) parece explicar esta situación de quimiorresistencia ${ }^{5}$

Yagoda revisó 83 ensayos clínicos publicados que incluían 4.093 pacientes tratados con qimioterápicos, demostrando una tasa de respuestas en únicamente el $6 \%$ de los pacientes siendo la vimblastina y el $5 \mathrm{FU}$ las drogas más activas, indicando que las combinaciones de gemcitabina y $5 \mathrm{FU}$ pudieran presentar en un futuro mayor tasa de respues$\operatorname{tas}^{6}$

Los agentes hormonales, medroxiprogesterona $y$ tamoxifeno, empleados desde que Kirkman descubrió en 1952 tumores renales estrogenoinducidos, a falta de otras terapias, se comprobaron ineficaces, con tasas de respuestas inferiores al 10\%

La radioterapia local aplicada tras la nefrectomía tampoco obtuvo efecto alguno positivo sobre la recidiva local. Tan solo se contempla actualmente su aplicación local sobre metástasis dolorosas y hemorrágicas, sobre todo óseas, buscando su efecto antiálgico y antiinflamatorio.

\section{MODELO TUMORAL CON IMPLICACIONES INMUNOLÓGICAS}

Existen múltiples datos para considerar al cáncer renal como el prototipo de tumor inmunogénico. Entre ellos es preciso citar la evidencia de regresiones espontáneas ya comunicadas en 1928 por Bumpus de la Clínica $\mathrm{Mayo}^{3}$ y al parecer confirmadas hasta en un $4 \%$ de pacientes por Oliver $^{3}$; la frecuencia elevada de lesiones metastásicas metacrónicas alejadas en el tiempo tras el diagnóstico; la asociación a varios síndromes y manifestaciones paraneoplásicas; las localizaciones tumorales en regiones infrecuentes poco habituales; y la posible respuesta a la acción inmunomoduladora con evidencia de estabilizaciones prolongadas y duraderas incluyendo respuestas completas en ciertos pacientes respondedores a la inmunoterapia ${ }^{8}$.

\section{INMUNOTERAPIA}

El objetivo de las intervenciones biológicas empleando elementos inmunes persigue la restauración de la normalidad, y su reprogramación, ya sea mediante la supresión o potenciación de las propias células inmunológicas ${ }^{8}$.

Las fases básicas y fundamentales en el desarrollo tumoral, de forma simple, son las que ignoran las señales de inhibición, evitando la apoptosis, estimulando la angiogénesis e invadiendo tejidos vecinos, junto al deterioro del proceso de inmunovigilancia. Aunque más profundos, conceptos modernos como inmunoedición, propia del tumor, por la que se expanden antígenos poco inmunógenos, e inmunosubversión, por la que se produce una supresión activa del sistema inmune se encuentran actualmente en plena expansión ${ }^{9}$.

El sistema inmunológico contribuye a la vigilancia y destrucción de células tumorales empleando para ello mediadores celulares con actividad antitumoral del tipo de las células asesinas naturales inespecíficas o Natural killer (NK), y linfocitos T citotóxicos (Fig. 1). Activando estas células mediante diversos procedimientos lograremos que nuestro propio sistema inmune intente el control tumoral, en forma similar a como los antígenos tumorales activan los linfocitos $T$ helper, poniendo en marcha todo el mecanismo inmunológico ${ }^{10}$.

Asimismo, en la actualidad se concede importancia a las células dendríticas peritumorales encargadas de capturar células necróticas tumorales, transportándolas hasta los ganglios linfáticos regionales donde activarán células $\mathrm{T}^{9}$.

Aunque escapa de este artículo el desarrollo en profundidad de los mecanismos por los que el tumor escapa a los mecanismos de vigilancia inmunológica, recordaremos que la activación del sistema inmune implica

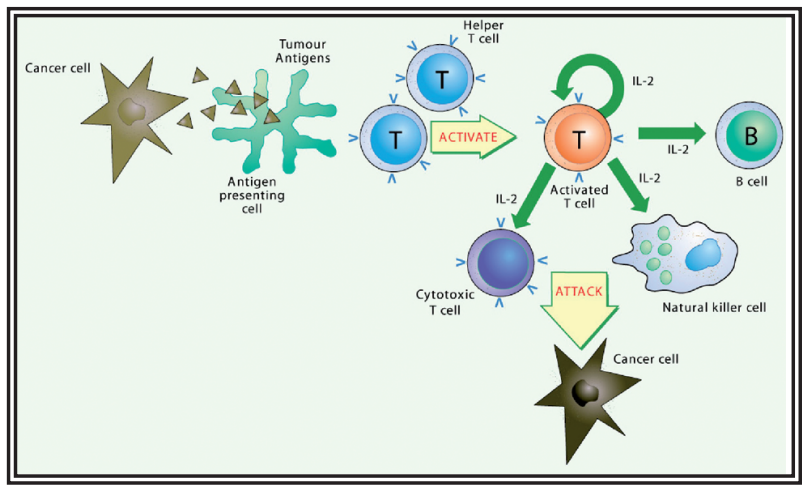

FIGURA 1. Sistema inmunológico (Amstrong A. Br Med J. 2001;329:1289). 
la secreción de citocinas, quimiocinas y diversos factores de crecimiento que pueden favorecer la proliferación celular tumoral. Además pueden producirse sustancias con actividad proteolítica e inflamatoria que aparte de producir daño tisular inducen la angiogénesis, mecanismo relacionado con la progresión local y paso obligado para la diseminación a distancia ${ }^{11}$.

La primera manipulación de orden inmunológico la desarrolló Montie en 1975 mediante la aplicación de BCG en forma de escarificaciones cutáneas, logrando respuestas objetivas entre el 14 y el $22 \%$ de los $\operatorname{casos}^{3}$.

De Kernion empleó RNA de linfocitos de sangre periférica de animales previamente inmunizados o contaminados con células tumorales específicas obteniendo 8 respuestas parciales en 25 pacientes $(32 \%)^{12}$.

En 1982 Oldham acuñó el término de "modificadores de la respuesta biológica" definiendo así a todos los fármacos, agentes naturales o sintetizados capaces de alterar la respuesta biológica organizada entre el tumor y el sistema inmune del huésped ${ }^{3}$.

En los inicios de los ochenta los grupos de De Quesada y de Quernion ${ }^{13}$ empleando interferon alfa y el de Rosemberg ${ }^{14}$ utilizando IL2 junto a linfocitos $\mathrm{T}$ estimulados con linfocinas fueron los pioneros en aplicar citocinas en el tratamiento del cáncer renal diseminado.

En su inicio estos tratamientos se pusieron en marcha optimistas ante la perspectiva de poder contar con terapias aptas y con resultados frente a pacientes con cáncer diseminado y también en aquellos que no estando diseminados presentaran datos desfavorables de agresividad.

El tejido tumoral renal se encuentra infiltrado abundantemente por linfocitos infiltrantes (TIL), produciendo una inmunosupresión caracterizada por hipoproducción de citocinas, unida a una disminución de la actividad lítica de las células T citotóxicas. La propia infiltración linfocítica peritumoral junto con el crecimiento evidente tumoral nos habla de una respuesta inmunológica alterada. Incluso se valora la posibilidad de que por parte del tumor, o como forma anómala de respuesta sistémica inducida por el tumor, los linfocitos TIL presenten defectos funcionales que los inhabilitan ${ }^{11}$.

Existen otros mecanismos complejos por los que factores angiogénicos, VEGF y bFGF inhiben la adhesión celular tumoral favoreciendo el escape inmunológico de la célula tumoral ${ }^{11}$.
La inmunoterapia frente al cáncer renal cuenta con diversas modalidades ${ }^{10}$ (Tabla 1) (Fig. 2), aunque no todas al alcance de todos los centros. Así la inmunoterapia adoptiva con células LAK y linfocitos LIT, la inmunoterapia activa específica, la terapia génica con vacunas tumorales, el empleo de anticuerpos monoclonales activos, y el trasplante de stem-cells hematopoyéticas alogénicas son terapias de uso en centros altamente especializados. La inmunoestimulación con citocinas sin embargo, disponible en cualquier centro hospitalario es de manejo no especialmente complicado, pudiendo administrarse en régimen ambulatorio.

Tabla 1. Modalidades actuales de la inmunoterapia Inmunoestimulación con citocinas Inmunoterapia adoptiva con células LAK y linfocitos LIT Inmunoterapia activa específica

Terapia génica con vacunas tumorales

Anticuerpos monoclonales activos

Trasplante de stem-cells hematopoyéticas alogénicas

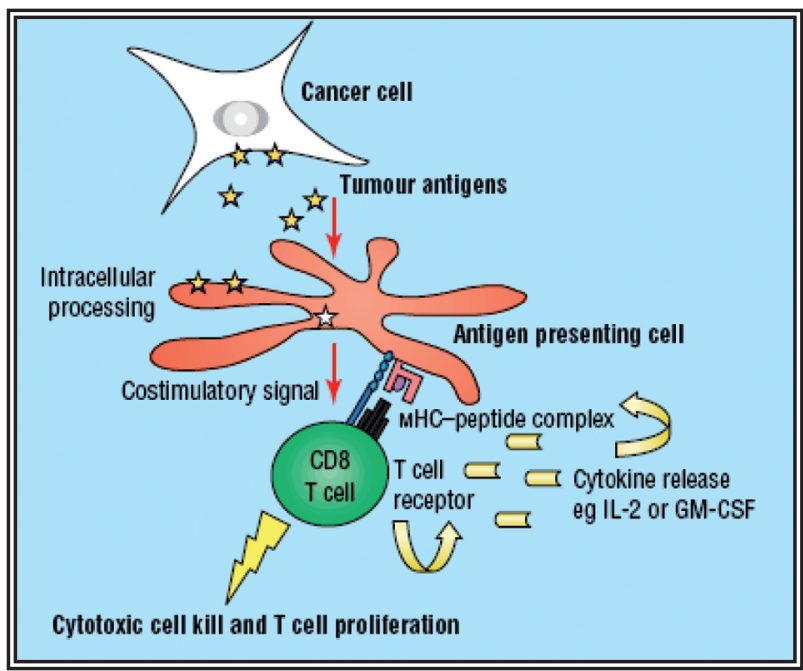

FIGURA 2. Posibilidades de inmunoterapia (Amstrong A. Br Med J. 2001;329:1289).

\section{INMUNOESTIMULACIÓN MEDIANTE CITOCINAS}

En la actualidad, y al alcance de todo centro encargado del manejo oncológico de pacientes afectos de cáncer renal diseminado o avanzado, están las citocinas. Son productos con efecto tumoricida directo que asimismo activan componentes efectores del sistema inmune. 
Desde 1950 se conoce la actividad antitumoral de los interferones (IFN), estudiándose poco después las interleukinas (ILK) ${ }^{15}$.

En esencia, la actividad de las citocinas consiste en la intermediación y modulación de la respuesta citolítica de los linfocitos frente a las células tumorales o los antígenos de las mismas, ya sea de forma espontánea o mediante la inducción al reconocimiento mediante vectores celulares. Se trata de factores inespecíficos de estimulación inmunitaria cuyo objetivo es el de inducir un estado de reactividad inmunológica generalizada incrementándose de esta manera la actuación citolítica tumoral del organismo ${ }^{16}$.

Existen varias citocinas. El factor de necrosis tumoral $(T N F-\alpha)$ presenta efecto directo lítico pero su administración exógena presenta graves efectos secundarios sistémicos. El interferon (IFN) induce la expresión de antígenos de superficie tumorales que pueden ser expuestos para su ataque por el sistema de vigilancia inmune, a la vez que se le reconoce un efecto antitumoral directo. También estimula a las células T citotóxicas, regulando a las células NK y a los macrófagos. La interleukina (ILK-2) conocida como factor de crecimiento de las células T, es producida por células $\mathrm{T}$ helper activadas ante un tumor, originando proliferación de células T citotóxicas y células asesinas (NK) capaces de lisar células tumorales autólogas, respetando las células normales. La IL-2 no posee, al contrario que el IFN- $\alpha$, efecto antitumoral directo, consiguiendo éste mediante la estimulación de células $\mathrm{NK}^{16}$.

$\mathrm{El}$ interferón aparte de actividad antivírica ejerce diversas funciones de inmunomodulación y regulación de la proliferación celular, mediante efecto antiproliferativo tumoral, inhibiendo también la angiogénesis. Se producen en las células monunucleares. Se han caracterizado 3 tipos, $\alpha, \beta y \gamma$. De ellos el IFN$\alpha$ es el que obtuvo en un principio ciertos resultados con tasas de respuesta que oscilaron entre el $10 \mathrm{y}$ el $25 \%^{13,17}$

La tecnología recombinante, mediante DNA de Escherichia Coli, ha conseguido producir para su uso en humanos dos subtipos de IFN- $\alpha$ : $2 a$ (Roferon $^{\circledR}$, Hoffman LaRoche, Suiza) y el $2 b$ (Intron ${ }^{\circledR}$, Schering Plough, USA). Ambos están compuestos de 165 aminoácidos, diferenciándose en el número 23, lisina en el 2a y arginina en el 2b. Las dosis óptimas no han sido aún claramente establecidas. Dosis de 2a de 5-20 MU/día 3 a 5 días a la semana, en aplicación subcutánea, parecen ser las mejor toleradas permitiendo obtener así una buena y aceptable respuesta. Esta pauta se logró establecer a partir de ensayos clínicos aleatorizados ${ }^{18,19}$ y tras el juicio crítico de análisis retrospectivos.

Se ha calculado que el tiempo hasta respuesta objetiva varía entre los 2 y 12 meses, por lo que la duración del tratamiento ha de mantenerse al menos 1 año para poder valorar respuesta, debiendo por tanto administrar dosis intermedias que sin perder efectividad hagan más tolerable el tratamiento, minimizando los efectos secundarios.

Los mejores resultados empleando interferón, en cuanto a tasa de respuesta y duración de la misma, se obtuvieron en pacientes con nefrectomía previa, vírgenes de tratamiento quimio o radioterápico, con buena situación funcional y con metástasis de preferencia pulmonares. En estos, la tasa de supervivencia aumentó de 49 a 115 semanas con IFN- $\alpha^{20}$.

El interferón puede desarrollar como efectos secundarios fiebre, escalofríos, mialgias, anorexia y cefalea, en general asociados al inicio del tratamiento, conocido como sindrome pseudogripal o influenza-like, desarrollándose posteriormente tolerancia y desaparición de los síntomas. Estos síntomas son fácilmente controlados con paracetamol. Además se han observado alteraciones hematológicas, anemia y plaquetopenia, y hepáticas, con elevación de transaminasas, que al igual que los efectos clínicos suelen desaparecer a lo largo del tratamiento.

El IFN puede ser químicamente modificado añadiéndole glicol-polietileno, produciendo IFN-pegilado, consiguiéndose un menor aclaramiento renal, lo que permite administrarlo una vez a la semana, manteniéndose la actividad inmunológica con una toxicidad aceptable y logrando respuestas 14-19\% con menos toxicidad ${ }^{21}$.

La interleukina se produce en los linfocitos CD4 activados, resultando esencial como factor de crecimiento para las células efectoras inmunológicamente activas como los linfocitos $\mathrm{T}$ y los NK. Se conocen desde 1976, 12 subtipos, siendo el tipo 2, ILK2, el que más se ha empleado y del que se reconocen mejores efectos, mayor tolerancia y menos efectos indeseables.

Al igual que el interferón, mediante tecnología de DNA recombinante se ha producido en el Escherichia Coli, IL2 apta para su uso humano (Proleukin ${ }^{\circledR}$, aldesleukina, Chiron, USA). La mayoría de los estudios se han desarrollado en tumores renales y melanomas. 
Uno de los graves problemas de la IL2 es su dosificación y la vía de administración. En 1992, en USA, se aprobó para el tratamiento en cáncer rena diseminado a dosis de 600.000-720.000 UI/kg en bolo intravenoso cada 8 horas, hasta lograr infundir 14 dosis, durante un período de 14 días. Los resultados obtenidos, en siete ensayos clínicos que reclutaron 255 pacientes con una tasa global de respuesta completa del 7\% y parcial del 8\%, permitieron ser optimistas ${ }^{22}$.

Los efectos secundarios de la IL2 con esta forma de infusión afectan varios órganos. Desde el riñón produciendo insuficiencia renal, al sistema cardiovascular y pulmonar, con hipotensión, taquiarritmias incluso edema pulmonar, al sistema nervioso con alteraciones en el estado mental, y al sistema gastrointestinal produciendo diarreas y hemorragia. Por ello se recomienda su administración en unidades de cuidados intensivos ${ }^{23}$.

Como consecuencia se han buscado diferentes maneras de administrar la ILK2, de forma intravenosa continua, subcutánea, incluso mediante inhalación pulmonar. No obstante la tasa de respuesta en un estudio que incluyó 261 pacientes fue significativamente mejor cuando se administraban altas dosis en bolo, 18\%, frente a bajas dosis, 7\%, o incluso en forma subcutánea con tasas del 11\%. Las dosis altas van acompañadas de una mayor duración de la respuesta. La respuesta se obtiene tras el $1^{\circ}$ ó $2^{\circ}$ ciclo, por lo que se aconseja parar el tratamiento si tras 2 ciclos no se obtiene respuesta. En caso de lograr respuesta la orientación actual sería continuar el tratamiento hasta la remisión completa o hasta la aparición de toxicidad ${ }^{24}$.

En un estudio de Yang se compararon dosis altas de ILK2 con dosis 10 veces menores administradas en forma endovenosa, obteniendo una tasa de respuestas similares, del $17 \%$ para la primera forma de administración y del 15\% para la segunda. Posteriormente otros estudios reuniendo un total de 256 pacientes de varios centros confirmaron los resultados de Yang ${ }^{25}$.

La alta toxicidad de la ILK2 obliga a intentar descubrir pacientes que pudieran mejor responder a esquemas que emplean inmunoterapia para poder asumir los riesgos que su aplicación implica. Datos preliminares sugieren que la expresión de anhidrasa carbónica IX en las células tumorales, reguladora del ph intray extracelular durante los períodos de hipoxia, así como una histología de células claras sin componente granular ni sarcomatoide parecen mejorar la respuesta a citocinas ${ }^{26}$.
Estudios inmunohistoquímicos demostraron que niveles inferiores al 85\% sugerían un factor independiente de mal pronóstico. Niveles mayores al $85 \%$ podrían presentar mejor respuesta a ILK2, por lo que esta situación podría ser considerada como factor pronóstico para el tratamiento con ILK2 $2^{27}$.

Existe un tipo de tratamiento denominado de combinación que asocia ILK2 e IFN $\alpha$, que busca reducir la toxicidad. En 1988 se comenzó con esta terapia en la UCLA obteniendo en 52 pacientes una tasa de respuesta del 25\%, con una duración de 23 meses y un promedio de supervivencia mayor de 34 meses. Los efectos secundarios fueron similares a los provocados con la terapia única, pero menores en intensidad ${ }^{28}$.

En 2006 la EORTC comenzó un estudio que pretende incluir 900 pacientes en tratamiento de combinación con IFN+ILK2 y 5 fluoracilo. Hasta 2010 no tendremos resultados, que en principio nos optimizarán las dosis y frecuencia de administración de las citocinas en un intento de lograr una mayor efectividad disminuyendo efectos secundarios ${ }^{21}$.

Los resultados de la inmunoterapia con citocinas son de aparición lenta, debiendo valorarse sus efectos varios meses después de su inicio. Está demostrado que las dosis intermedias son mas efectivas que las bajas, igualando a las altas en resultados, pero con menos efectos adversos. Como ya se ha comentado la terapia ha de mantenerse hasta lograr la remisión completa o hasta la aparición de toxicidad no tolerable.

\section{COMPARACIÓN DE LA INMUNOTERAPIA CON DIFERENTES TRATAMIENTOS}

Todos los fármacos nuevos y antiguos ya sean agentes citostáticos como nuevas moléculas dianas, se han comparado con interferon o interleukina2. Así, el IFN se testó junto a vimblastina comparando esta asociación a la propia vimblastina sola ${ }^{29}$ con resultado claramente superior a favor de la asociación. También se comparó frente a frente al acetato de medroxiprogesterona, en un estudio con 335 pacientes asignados aleatoriamente a IFN $\alpha$ y 10 millones a 3 dosis semanales durante 12 semanas $(\mathrm{n}=174)$ frente a medroxiprogesterona $300 \mathrm{mg}$ al día durante 12 semanas ( $n=176)$, obteniendo un $28 \%$ de reducción de riesgo de muerte en el grupo de IFN con ganancia de $12 \%$ en la supervivencia a 1 año de IFN frente a medroxiprogesterona $31 \%$ frente a $43 \%$ ) y un aumento de la media de supervivencia de 
2,5 meses ${ }^{30}$. Asimismo en un estudio de Motzer ${ }^{31}$ se comparó en monoterapia a la asociación con ácido 13-cisretinoico no logrando establecer beneficio positive a favor de la combinación. Sin embargo en el estudio EORTC $30951^{32}$, se observa prolongación significativa de la media de progresión en el grupo de asociación 5,1 meses frente a 3.4 meses, con una supervivencia de 17,3 frente a 13,2 meses.

Se compararon las altas dosis de ILK2 con las bajas asociadas a IFN $\alpha 2 \mathrm{a}^{33}$ resultando un $17 \%$ de primeras respuestas frente al $11 \%$ a favor de las altas dosis, pero igualándose el porcentaje de respuestas a largo plazo. También existe un estudio francés en el que se comparó la ILK2 en infusión continua, al IFN alfa $2 \mathrm{a}$, y a su vez a la asociación de ILK2 en infusión continua junto a IFN $\alpha 2 \mathrm{a}^{34}$ en el que demuestran sobre 405 pacientes un mayor porcentaje de respuestas al año, del $20 \%$ a favor de la terapia de combinación. Existe otro estudio, conocido como PERCY, del mismo grupo, que comparó la infusión endovenosa de ILK2 e IFN con la asociación de ILK2 en administración subcutánea e interferón ${ }^{35}$ no encontrando diferencias entre las dos formas de administración.

Dado el carácter de fármaco básico del IFN, más recientemente se ha comparado en diferentes estudios a sunitinib ${ }^{36}$ donde éste produce respuestas evaluables del 31\% frente al 6\% del primero, aportando además una mejoría en la calidad de vida; asociado a bevacizumab en el estudio AVOREN enfrentado a IFN donde la primera forma de asociación presenta un período libre de progresión de 10,2 meses frente a 5,4 de la segunda ${ }^{37}$; y a temsirolimus $^{38}$ en diferentes dosis asociadas o no a IFN, demostrando una mejor supervivencia cuando se administra el temsirolimus solo, de 10,9 meses frente a 7,3 meses cuando el paciente recibe solo IFN; a sorafenib en el estudio TARGET ${ }^{39}$ aunque en este estudio no se compara directamente con IFN sino que compara los resultados con los ofrecidos en estudios previos de IFN. En todos ellos, y en varios recientemente presentados en ASCO 2008, muchos aún en fase II, los nuevos fármacos se demuestran superiores a la inmunoterapia clásica.

\section{CIRUGÍA CITORREDUCTORA ASOCIADA A INMUNOTERAPIA}

La mejoría de la calidad de vida, evitando síntomas locales en el paciente parece un argumento a favor de la nefrectomía en tumores diseminados. A pesar de no estar del todo claro los mecanismos por los que la nefrectomía redunda en beneficio en cuanto a supervivencia, cuando se sigue de tratamiento con IFN, dos son los estudios básicos reseñables que ayudan a establecer la necesidad de cirugía renal a pesar de la diseminación en el momento diagnóstico.

El SWOG 8949 (Southwest Oncology Group) ${ }^{40}$ y el EORTC 30947 (European Organization for Research and Treatment of Cancer $)^{41}$ demostraron un beneficio en supervivencia media en el primero de 11,1 meses frente a 8,1 meses, y de 17 frente a 7 meses en el segundo. La nefrectomía previa seguida de tratamiento con IFN mejoraba la supervivencia global independientemente del performance status del paciente, la localización de las metástasis y la presencia de enfermedad medible. Una hipótesis para responder a esta evidencia es la de que el tumor primario es capaz de segregar sustancias inmunosupresoras que disminuyen la eficacia de la inmunoterapia, por lo que la nefrectomía puede incrementar la supervivencia y retrasar la progresión, incrementando la respuesta al tratamiento sistémico.

La ILK2 a dosis altas con eventual cirugía de rescate de lesiones metastásicas obtiene entre un 5-7\% de respuestas completas mantenidas y un 10-15\% de pacientes con largas supervivencias, por lo que este tratamiento debe ser considerado en pacientes con pronóstico favorable, sin metástasis cerebrales, enfermedades autoinmunes ni disfunción cardíaca severa $^{35}$.

\section{RECOMENDACIONES ACTUALES EN GUÍAS CLÍNICAS}

En nuestro medio disponemos de las Guías Clínicas de la Asociación Europea de Urología publicadas en referencia al cáncer renal en 2007, punto obligado para establecer unas pautas de actuación ${ }^{42}$.

Las propias guías no establecen categóricamente niveles en cuanto a pronóstico, pero se considerarían los tumores de mejor pronóstico, en cuanto a tratamiento sistémico se refiere, aquellos compuestos de células claras, previamente nefrectomizados, con un grado celular bajo, con metástasis en un solo órgano, de preferencia pulmonares, y con un tiempo de latencia entre diagnóstico y nefrectomía superior a los 12 meses, buen estado general, y con determinaciones analíticas dentro de límites normales. 
Respecto al beneficio de realizar nefrectomía en tumores diseminados nos indican que ésta se deberá practicar cuando el estado general del paciente sea bueno, y sea seguida de inmunoterapia con IFN, situación que mantiene un nivel de evidencia $1 b^{42}$.

La terapia inmunológica adyuvante, entendida por aquella administrada al paciente con enfermedad localizada de alto riesgo, a partir de pT3, no se encuentra en la actualidad recomendada (grado de recomendación A) por cuanto no supone un aumento de supervivencia (nivel de evidencia $1 b$ ).

Cuando se detecten metástasis asincrónicas con largo intervalo de aparición superior a los 2 años, o lesiones residuales, deberán resecarse, no estando recomendada la administración de inmunoterapia por cuanto no incrementa el pronóstico (nivel de evidencia 2b), siempre que las lesiones sean limitadas $\mathrm{y}$ accesibles quirúrgicamente.

Ya que la ILK2 no ha demostrado ser superior al IFN, incluso en regímenes de altas dosis, su uso no se recomienda (nivel de evidencia $1 \mathrm{~b}$ ), siempre que se emplee el IFN $\alpha$ subcutáneo a dosis de 10 millones UI 3 veces por semana y durante 12 semanas. Con esta pauta el porcentaje de respuestas será de 6-15\%, junto a una disminución del 25\% en el riesgo de progresión tumoral, lográndose un beneficio de 3-5 meses en la supervivencia ${ }^{43}$.

En las guías no se hace referencia al tratamiento mediante inhalación de ILK2 indicada en pacientes con metástasis pulmonares en los que no exista otra opción terapéutica. En nuestro país se realizó un estudio que reclutó 51 pacientes afectos de metástasis pulmonares no resecables tratadas con ILK2 en forma inhalada. Se logró un 13,7\% de respuesta objetiva, con una mediana de supervivencia de 8,6 meses y una supervivencia global de 23 meses $^{44,45}$.

Las propias guías aventuran el futuro del tratamiento médico del cáncer renal diseminado, con unos niveles de evidencia altos, y basados en estudios recientes, recomendando el uso de inhibidores de la tirosinkinasa, sorafenib en $2^{\text {a }}$ línea tras inmunoterapia en tumores de buen pronóstico, y sunitinib como primera opción de tratamiento en tumores de riesgo intermedio, reservando el temsirolimus como primer escalón terapéutico en tumores de pobre pronóstico ${ }^{36}$.

Otras guías clínicas como la de BC Cancer Agency de Canadá ${ }^{46}$ y la del National Cancer Institute de $\mathrm{USA}^{47}$ se hacen eco unas a otras de las mismas recomendaciones. En esta última, curiosamente el IFN y la ILK2, incluso en combinación, se aconsejan ante la progresión o ausencia de respuesta a los modernos fármacos en tumores renales compuestos predominantemente de células claras.

Probablemente un futuro más o menos inmediato nos hará disponer de nuevos fármacos efectivos en el manejo de este tipo de tumor, adaptando su uso a los distintos tipos tumorales referidos siempre al pronóstico individualizado de cada uno de ellos.

Aunque sea aventurado siquiera apuntarlo, actualmente se vislumbra un desarrollo vertiginoso de fármacos tumoricidas, como los inhibidores de la angiogénesis, ya disponibles y aprobados para su uso clínico, y de otros como temsirolimus, lapanitib, bevacizumab, axinitib, neovastat etc, que igualando y superando la eficacia del IFN $\alpha$, sean mejor tolerados por el paciente. Es probable que esta situación haga entrar en el olvido la inmunoterapia con IFN $\alpha$ e ILK2 en el manejo, siempre complicado y sorprendente, del cáncer renal. No obstante hay autores que preconizan un primer intento de tratamiento inmunoterápico a fin de lograr períodos de estabilización en el curso de la enfermedad, reservando los modernos tratamientos para una segunda línea ${ }^{5}$. En definitiva se trata de agotar una línea de tratamiento que, a pesar de escasa respuesta, cuando ésta se alcanza puede ser duradera en el tiempo ${ }^{48}$.

Como colofón parece interesante apuntar las líneas actuales empleadas para el manejo del cáncer renal diseminado ${ }^{2}$. Para los tumores de células claras, con metástasis pulmonares, en los que éstas han aparecido más allá del año del diagnóstico, con buen performance status, y nefrectomía previa (Tabla 2) estaría indicado el tratamiento con IFN $\alpha$ a dosis de 9 millones UI 3 veces por semana, en aplicación subcutánea, durante 12 semanas, evaluando tras éste período la respuesta, y no estando clara la duración del tratamiento o si se debe realizar terapia de mantenimiento.

Para aquellos tumores que presenten 3 o más factores de mal pronóstico de los siguientes (LDH $>$ 1,5 límite normal, hemoglobina $10 \mathrm{~g} / \mathrm{dl}$, intervalo menor a 1 año entre el diagnóstico y la diseminación, Karnofsky $\leq 70$, o metástasis en $\geq 2$ órganos distintos) están indicados los modernos tratamientos médicos, incluyendo algunas pautas combinaciones de éstos con IFNa ${ }^{38}$. 
Tabla 2. Factores pronósticos de respuesta favorable a la inmunoterapia basada en citocinas

Karnofsky $\geq 80 \%$

Nefrectomia previa

Metástasis metacrónicas $\geq 6$ meses respecto al diagnóstico inicial

Intervalo libre sin tratamiento $\geq 12$ meses respecto al dignóstico inical

Metastasis en un solo órgano

Localización metastasica pulmonar

HB en niveles normales

Niveles de LDH inferiores a 1,5 veces su valor normal

Calcio corregido $<10 \mathrm{mg} / \mathrm{dl}$

(Campbel SC, Novick AC, Bukowski RM. Renal tumors. In Campbell-Walsh Urology $9^{\text {th }}$. Ed Philadelphia Saunders 2007 pp 1567-1637)

\section{JUSTIFICACIÓN PARA EL EMPLEO DE INMUNOTERAPIA}

Precisamente respuestas ocasionalmente espectaculares por su duración, a la manipulación inmunológica, son las que hacen atractiva la utilización de citocinas en pacientes afectos de diseminación tumoral por células renales, al menos en primer lugar tras el diagnóstico, antes de pasar al siguiente escalón terapéutico moderno y en principio con mayor índice de respuesta, pero de necesaria y continua administración, no exenta de efectos secundarios, aparte del coste económico que suponen.

Aunque para algunos autores las respuestas a la inmunoterapia son paupérrimas, para otros, a pesar de no obtener resultados espectaculares, presentan relevancia clínica que pueden llegar a incluir respuestas completas, que aunque escasas, son inalcanzables con otros regímenes terapéuticos ${ }^{48}$.

La inmunoterapia era hasta hace poco tiempo la única modalidad que obtenía ciertos resultados en el tratamiento del cáncer renal diseminado, no conseguidos por otros tipos de tratamiento. Muy probablemente en un futuro inmediato las nuevas moléculas dirigidas a nuevas dianas superen los resultados de la primera, aunque la inmunoterapia seguirá pudiendo ofrecer a pacientes concretos largas remisiones. Por otra parte, y sin entrar a valorar motivos económicos, seguirán existiendo pacientes que se beneficiarán de un tratamiento más corto en duración, con relativa buena tolerancia, reservando las nuevas moléculas para la progresión, si ocurriera.

\section{FUTURO DE LA INMUNOTERAPIA}

A pesar del uso y efectividad de las nuevas moléculas, se sigue probando el empleo de nuevas interleukinas, concretamente la 7 y la 15, que estimulan la proliferación de células $\mathrm{T}$ de memoria , inhibiendo "inhibidores" inmunológicos ${ }^{49}$.

Muy probablemente y en razón de las últimas comunicaciones presentadas en ASCO $2008^{50}$ tanto la ILK2 como el IFN encontrarán un relevante puesto terapéutico en asociación con las nuevas moléculas, buscando elevar la eficacia obteniendo mejores resultados, permitiendo reducir las dosis de ambos fármacos, logrando así disminuir los efectos indeseables. Además, existen opiniones a favor de que los nuevos fármacos solo tienen un efecto "tumorostático”, por lo que sería interesante a priori unirlos a productos "tumoricidas", como por ejemplo el interferón ${ }^{51}$.

\section{REFERENCIAS}

1. Robson CJ. Radical nephrectomy for renal cell carcinoma. J Urol 1963; 89:37-42.

2. Campbell SC, Novick AC and Bukowski RM. Renal tumors. In CampbellWalsh Urology. 9th Ed Philadelphia Saunders 2007; pp 1567-1637.

3. Cozar JM, Tallada M, Espejo E, y Vicente J.: Estado actual de la inmunoterapia en el cáncer renal diseminado. Rev Urol 2002; 2: 62-72.

4. Stadler WM, Huo D, George C, Yang X, Ryan CW, Karrison T, Zimmer man TM, Vogelzang NJ.: Factores pronósticos para la supervivencia en el cáncer renal metástasico tratado con gemcitabina y 5-fluoracilo. J Urol 2003;170(4 Pt 1):1141-1145.

5. Sokoloff MH, Figlin RA y Belldegrun AS: Tratamiento del carcinoma metástasico de células renales. AUA update series 1996; volume XV, lección 30: 156-62. Poner cita tambien en inglés

6. Yagoda A, Petrilak D, Thompson S: Cytotoxic chemotherapy for advanced renal cell carcinoma. Urol Clin North Am. 1933;20(2):303321.

7. Yagoda A, Abi-Rached B, Petrylak D. Chemotherapy for advanced renalcell carcinoma: 1983-1993. Semin Oncol 1995; 22:(1)42-60.

8. Carballido J, Oliver C. Tratamiento del carcinoma renal metastático. En Tratado de Oncología Urológica. Resel L, Moreno J eds. Sanidad y Ediciones sl 2003. cap 31: 399-413.

9. Rosenberg SA, Yang JC, Restifo NP.: Cancer inmunotherapy: moving beyond currrent vaccines. Nat Med 2004;10(9):909-915.

10. Amstrong A. Eaton D and Swing JC. Science, medicine and the future: cellular immunotherapy for cancer. Br Med J 2001;329:1289.

11. Carballido J, Alvárez-Mon M. Inmunología y Urología. En Tratado de Urología. Jiménez Cruz F y Rioja LA (eds) Barcelona Prous Science 2006,cap 93:1773-1787.

12. DeKernion JB, Ramming KP, Smith RB. Natural history of metastatic renal cell carcinoma. J Urol 1978;120(2):148-152.

13. Quesada JR, Rios A, Swanson D et al.: Antitumor activity of recombinat derived interferon alpha in metastatic renal cell carcinoma. J Clin Onco 1985;3(11):1522-1528

14. Rosemberg SA, Lotze MT, Muul LM et al.: Observtions on the systemic administration of autolous lymphokine-activated killer cells and recombinant interleukin-2 in patients with metastatic cancer. N England $J$ Med 1985;313:1485-92.

15. Isaacs A, Lindenmamm J. Virus interference. I. The interferon. J Interferon Res 1987;7(5):429-438.

16. Gitlitz BJ, Figlin RA. Las citocinas en el tratamiento del carcinoma renal metastático. Urol Clin North Am 2003;30(3):589-600. 
17. Neidhart J, Gagan M, Young D.: Interferon-alpha therapy of renal cancer. Cancer Res 1984;44(9):4140-4143.

18. Muss HB, Costanzi JJ, Leavitt R, Williams RD, Kempf RA, Pollard R, Ozer H, Zekan PJ, Grunberg SM, Mitchell MS, et al.: Recombinant alfa interferon on renal cell carcinoma: a randomized trial of two routes of administration. J Clin Oncol 1987;5(2):286-291.

19. Krown SE: Interferon treatment of renal cell carcinoma: current status and future prospects. Cancer 1987;59(3Suppl):647-651.

20. Logothetis C: Treatment of chemotherapy-refractory metastatic urothelial tumours. Urol Clin North Am 1992; 19(4):775-777.

21. Parton M, Gore M, Eisen T. Role of cytokine therapy in 2006 and beyond for metastatic renal cell cancer. J Clin Oncol 2006;24(35):5584-5592.

22. Fyfe G, Fisher RJ, Rosenberg SA et al.: Results of treatment of 255 pacientes with metastatic renal cell carcinoma who receive high-dose recombinant interleukin-2 therapy. J Clin Oncol 1995;13(3):688-696.

23. Gitlitz BJ, Hoffman DM, Moldawer N, Belldegrun A, Figlin RA.: Treatment of metastatic renal cell carcinoma with high dose bolus interleukin-2 in a non-intensive care unit: an analysis of 124 patients consecutively treated patients. Cancer 2001;7(2):112-120.

24. Figlin RA: Renal cell carcinoma: current status and future plans. Cancer J Sci Am 2000;6 Suppl 1:S52-4.

25. Yang JC, Topalian SL, Parkinson D, Schwartzentruber DJ, Weber JS, Ettinghausen SE, White DE, Steinberg SM, Cole DJ, Kim HI, et al.. Randomized comparison of high-dose and low-dose intravenous interleukin-2 for the therapy of metastatic renal cell carcinoma. J Clin Oncol 1994;12(8):1572-1576.

26. Atkins M, Regan M, McDermott D, Mier J, Stanbridge E, Youmans A, Febbo P, Upton M, Lechpammer M, Signoretti S. carbonic anhydrase IX expresión predicts outcome of interleukin2 therapy for renal cancer. Clin Cancer Res 2005;11(10):3714-3721.

27. Lam JS, Pantuck AJ, Belldegrum AS Figlin RA. G250: a carbonic anhydrase IX monoclonal antibody. Curr Oncol Rep 2005;7(2):109-115.

28. Figlin RA, Belldegrun A, Moldawer N, Zeffren J, deKernion J. Concomitant administration of recombinant human interleukin-2 and recombinant interferon alfa-2a: an active outpatient regimen in metastatic renal cell carcinoma. J Clin Oncol 1992;10(3):414-421.

29. Pyhonen S, Salminen E, Ruulu M et al. Prospective randomized trial of interferon alfa 2a plus vimblstine versus vimblastine alone in patients with advanced renal cell cancer. J Clin Oncol 1999;17(9):2859-2877.

30. Medical research council (MRC) renal cancer collaborators. Interferon alpha and survival in metastatic renal carcinoma. Early results of a randomized controlled trial. Lancet 1999: 2;353(9146):14-17.

31. Motzer RJ, Murphy BA, Bacik J, Schwartz LH, Nanus DM, Mariani T, Loehrer P, Wilding G, Fairclough DL, Cella D, Mazumdar M. Phase III trial of interferon alfa $2 \mathrm{a}$ with or wiyhout 13-cisretinoic acid for patients with advanced renal cell carcinoma. J Clin Oncol 2000;18(16):2972 2980 .

32. Aass N, De Mulder PH, Mickisch GH, Mulders P, van Oosterom AT, van Poppel H, Fossa SD, de Prijck L, Sylvester RJ. Randomized phase II / III trial of interferon alfa $2 \mathrm{a}$ with or wthout 13 cis-retinoic acid in patientes with progressive metastatic renal cell carcinoma. The European Organisation for research and Treatment of Cancer Genito-Urinary Tract Cancer Group (EORTC 30951) J Clin Oncol 2005;23(18):41724178.

33. McDermott DF, Regan MM, Clark JI, Flaherty LE, Weiss GR, Logan TF, Kirkwood JM, Gordon MS, Sosman JA, Ernstoff MS, Tretter CP, Urba WJ, Smith JW, Margolin KA, Mier JW, Gollob JA, Dutcher JP, Atkins MB.: Randomized phase III trial of high dose ILK2 versus subcutaneous ILK2 and IFN in patients with metastatic renal cell cacinoma. J Clin Oncol 2005;23:133-141.

34. Negrier S, Escudier B, Lasset C, Douillard JY, Savary J, Chevreau C et al. Recombinant human interleukin-2, recombinant human interferon alfa- $2^{\text {a }}$ or both in metastatic renal- cell carcinoma. N Engl J Med 1998; 30;338(18):1272-1278.

35. Negrier S, Perol D, Ravaud A, Bay JO, Oudard S, Fargeot P et al for the French Immunotherapy Intergroup. Is intravenous (iv) IL2 superior to subcutaneous(sc) IL2 in good prognosis patients (pts) with metastatic renal cell carcinoma (MRCC) receiving a combination of IL2 and alpha interferon (IFN)? Results of the prospective randomized PERCY Duo trial. $J$ Clin Oncol 2006;24 (18S) Supl ASCO Annual Meeting Proceedings Part I) 453.

36. Hudes G, Carducci M, Tomczak P, Dutcher J, Figlin R, Kapoor A, et al. Temsirolimus, interferon alfa, or both for advanced renal cell carcinoma. N Engl J Med 2007; 356: 2271-2281.

37. Escudier B, Koralewski P, Pluzanska A et al: A randomized, controlled, double-blind phase III study (AVOREN) of bevacizumab/interferon- $\alpha 2 a$ vs placebo/interferon- $\alpha 2 \mathrm{a}$ as first-line therapy in metastatic renal cel carcinoma. Journal of Clinical Oncology, 2007 ASCO Annual Meeting Proceedings Part I. Vol 25, No. 18S (June 20 Supplement), 2007:3.

38. Hudes G, Carducci M, Tomczak P et al : Temsirolimus, interferon alfa, or both for advanced renal-cell carcinoma. N Engl J Med 2007;31; 356 (22):2271-2281.

39. Escudier B, Eisen T, Stadler WM, Szczylik C, Oudard S, Siebels M, Negrier S, Chevreau C, Solska E, Desai AA, Rolland F, Demkow T, Hutson TE, Gore M, Freeman S, Schwartz B, Shan M, Simantov R, Bukowski RM; TARGET Study Group for the TARGET Study Group. Sorafenib in advnaced clear-cell renal-cell carcinoma. N Engl J Med 2007;356:125-34.

40. Flanigan RC, Salmon SE, Blumenstein BA, Bearman SI, Roy V, McGrath PC, Caton JR Jr, Munshi N, Crawford ED.. Nephrectomy followed by interferon alfa-2b alone for metastatic renal-cell carcinoma. N England J Med 2001;345:1655-1659.

41. Mickisch GHJ, Garin A, van Poppel H, ed Prick L, Silvestre R and members of the european Organisatin for research and Treatmente of Cancer (EORTC) Genitourinary Group. Radical nephrectomy plus interferonalpha based immunotherapy compared interferon-alpha alone in metastatic renal- cell carcinoma. A randomized trial. Lancet 2001;358 (9286)986-70.

42. Ljungberg B, Hanbury DC, Kuczyk MA, Merseburger AS, Mulders P, Patard JJ et al. Renal cell carcinoma guideline. European Urology 2007;51:1502 1510. (Traducción del artículo en Actas Urol Esp. 2009;33(3):270-279).

43. Coppin C, Porzsolt F, Autenrieth M, Kumpf J, Coldman A and Wilt T: Inmunothearpy for advenced renal cell cancer. Cochrane Database Syst Rev 2005; (1):CD001425.

44. Esteban-González E, Carballido J, Navas V, Torregrosa Z, Muñoz A, de Mon MA; PortugueseSpanish Inhaled IL-2 Group. Retrospective review in patients with pulmonary metastases of renal cell carcinoma receiving inhaled recombinant ILK2. Anticancer Drugs 2007;18(3):291-296.

45. Huland E, Hinzer M, Mir TS, Huland H. Inhaled interleukin-2 therapy in pulmonary metastatic renal cell carcinoma. Six years of experience. Cancer J Sci Ann 1997;3 Suppl 1:S98-105.

46. BCCancerAgency. http://www.bccancer.bc.ca/HPI/Cancer ManagementGuidelines/Genitourinary/Kidney.

47. National Cancer Institute. http://www.cancer.gov.

48. Yang JC and Childs R: Inmunotherapy for renal cell cancer. J Clin Oncol 2006;24(35):5576-5583.

49. Ruiz-Cabello F y Cózar JM: tratamiento del cáncer renal actualmente: estado del arte. Controversias y evidencias en Urología Oncológica 2007 6:3-10

50. ASCO Annual Meeting Abstracts. J Clin Oncol 2008; 26, issue 15S.

51. Lane BR, Rini BI, Campbel SC and Novick AC. Tratamiento dirigido molecularmente para el cáncer renal. AUA Update series 2008;26(10): 103-112.

Correspondencia autor: Dr. Roberto Llarena Ibarguren

Servicio de Urología. Hospital de Cruces

Plaza de Cruces, s/n - 48903 Barakaldo - Vizcaya

Tel.: 946006000

E-mail autor: rllarena@euskalnet.net

Información artículo: Original

Trabajo recibido: marzo 2009

Trabajo aceptado: abril 2009 